\title{
Study of the complexity factors associated with the theory of complexity in Iraqi construction projects
}

\author{
Hayder F. Abbas ${ }^{1}$, Kadhim R. Erzaij ${ }^{2}$ \\ 1Departement of civil engineering, College of engineering, Al-Farabi University College, Iraq \\ 2Departement of civil engineering, College of engineering, University of Baghdad, Iraq
}

\begin{abstract}
The process of studying the complexity factors associated with the theory of complexity is one of the required study and it is importance in the construction sector in Iraq. The Complexity Theory can be understood as the study of how order and pattern emerge from chaotic systems, conversely, how complex structures and behaviors emerge from simple rules. The complexity cognizes us how to contemplate about the development process. This paper introduces a brief outcome through identification complexity factor and review the previous studies to obtain the technical outcomes about the complexity theory. The studying complexity factors related with construction projects as be part to cover complexity thinking in construction project. The results of this study show that viewing of all these areas related to the complexity of the project and how it can help the management departments in construction projects in Iraq to understanding the complexity level of their project to put best construction management plans. Many engineers and experts participated in the presentation of the study outputs, and by drawing on their opinions to participate in the closed questionnaire. The participants were (engineers in construction sites, academics, engineering management experts, and technicians with direct relationship to construction projects). Based on the frequency analysis aspect, the order of the influencing factors was reached according to its rating from (poor to strong) which reflects the conclusions associated with the study. The importance of studying these factors on knowing the degree of complexity in construction projects and developing appropriate methodology for managing them.
\end{abstract}

\begin{tabular}{ll}
\hline Keywords: & $\begin{array}{l}\text { Complexity theory, Project complexity, Project complexity factors, Complexity in } \\
\text { project. }\end{array}$ \\
\hline
\end{tabular}

\section{Corresponding Author:}

Hayder F. Abbas

Depratment of civil engineering, College of Engineering,

Al-Farabi University College, Baghdad, Iraq.

dr.hayderfadhil2018@yahoo.com

\section{Introduction}

Construction projects are inherently complex and associated with an influential group of work parties that increase the degree of their complexity. It is through studying complexity theory that we can find that the complexity theory developed from systems theory and chaos theory in an attempt to show why the whole world is larger than the sum of parts and how all its parts are combined with one another to create comprehensive patterns as the machine advances and adapts. Complex technology tries to describe and simulate systems that are not able to be understood throughout traditional scientific believed patterns [1]. It is crucial to split between two ideas, namely "complexity program" and "complicated program", which might look similar. The author draws variance between your systems referring to the foundation of words, i.e. complex origins from Latin "cum plexus", which means "restricted up with" implying interactions and 
interrelations, whereas complicated originates from Latin "cum-pliare", meaning "piled up with", implying disconnection and favouring reduction approach [2]. To better understand complex and complexity theory, publications linked to complexities in structure projects will be reviewed. The complexity management may also be examined to regulate how the complexity of the task is covered in a variety of previous research efforts [3].

There are various definitions that illustrate the complexity. It begins from the simplest and easiest to define that the operational system includes a number of elements. These elements are linked to complex interactions. Complexity is a way of measuring the amount of interrelation and interdependence which will affect your choice making process [4].

Complexity theory, referred to as complex systems theory. Systems theory can be an interdisciplinary field of research that studies the type of complicated systems in society, character, science, and technology [5].

Complexity is a one aspect of any task; theory of complexity assists comprehend the sociable attitudes of staff and systems of individuals involved with and in a close place of task. The ideas apply similarly to small projects concerning large complicated tasks - 'complexity' isn't a synonym for difficult or large [6].

One of many features of the complexity theory is that it allows an useful conceptual framework for dynamic and flexible analysis which in turn would be effective for carrying out more comprehensive studies [7].

Theory of complexity has become a fundamental system for the realization of complex interdisciplinary conditions and can be understood as the study of how order and methods arise from apparently chaotic systems and conversely how complex behavior and structures engender from simple basic rules. Several ideas manifest directly relevant to understanding project management from a relationship perspective [6]. It can also be pointed out that there is a complex set of factors, including which effects on complexity theory and complex projects while both of them are covering a wide range of natural, social and economic phenomena and those effect on study the complex projects. The increasing degree of complexity in projects, the need for more complexity systems in contracting methods and purchasing materials may increase, which must be closer to the sustainable level in order to achieve environmental requirements on the one hand, and profit and economic requirements on the other hand, so that projects of complexity degree are employed appropriately to contracting requirements [8]. Thus reducing the level of influence of factors associated with an increase in the degree of complexity.

\section{Objectives of the study}

-Study the complexity theory in construction projects through literature reviews.

- Determine a set of factors affecting the applications of complexity theory in construction projects.

- Define a set of factors that lead to an increase in the degree of complexity in construction projects.

- Reaching of the final results through the closed questionnaire.

- The logical conclusions related to the subject of the study and based on the results of the study.

\section{Literature review}

The following literary survey through previous studies gives a visualization of the importance of the theory of complexity and the factors with an impact directly or indirectly related to it.

In complexity theory, construction projects complexity has been discussed by many authors. Researchers have also conducted a surveys with various objectives to distinguish how project managers manage projects according to complexity theory approach. And arrive at a set of factors associated with the theory. The complexity is strongly connected with enterprise outputs and thereafter enterprise failure and success elements. Personality is rooted in these connotations, as well as effected by sectoral, educational and geographical variances. The study focused on the analysis of the set of fiasco factors by using group of techniques, consequently obtaining various styles about the conception of enterprise managers on affecting 
enterprise fiasco reasons and complexity of project. The analysis process is established on a survey made amongst project manager from all around the world to collect data on the influence degree of various elements related to projects failure. There are five groups and at least three obvious styles of answers in the observed population. The preponderant order of influence is factors of project, organization factors, manager of project and team member's factors, and outer factors [9].

For understanding and managing of complexity through The results are: 1) the framework of complexity is effective in supporting understanding. 2) to a certain extent, managers were able to differentiate strategies to minimize the majority of the complexities they faced. 3) The workshops identified a classification of responses to the remaining complexities. The complexity can be minimized and provide a means of assessing responses to remaining complexities, including the possibility of linking managers to projects [10].

The construction projects are becoming more and more complex, there was growing attention about the concept of project complexity. Complexity effects planning and control of construction project; it can prevent the identification of objectives and goals; it can influence the chosen of a convenient form of project organization, or could influence project outputs [11].

\section{The ingredients of complexity theory}

Complexity theory has ingredients issues and difficulties are [12]:

1) Complexity must be used authentically, not as a loose metaphor, as appears to be the case in a few management literatures (however, I really believe the concepts are for helping visitors to perceive and imagine circumstances differently).

2) In addition to studying the factors that contribute to the success of the theory or increase the degree of creativity in its use.

3) Many practitioners remark that Complexity Theory is conceptually interesting, but seems difficult to use in practice.

4) Enthusiasm for complexity concepts can result in a polarizing, 'two valued logic', glorifying this 'new paradigm' thinking and dismissing everything linked to the 'aged paradigm' (often characterized while Newtonian).

\section{Complexity theory in construction projects}

The opinion of defines the managers work as persons who prepare a transparent eyesight for the enterprise, provide fuctional leadership, communicate and promote organizational objectives, and present a grounds for open communication instead of becoming involved in planning for an unpredictable future, make detailed decision, and people controlling [13]. This requires a broad understanding of the complexity theory by the managers working in construction projects. The importance of complexity to the project management process is widely acknowledged [14]:

1) Complexity of project facilitate determination of planning, coordination and control requirements.

2) Complexity of project block the transparent identification of objectives and goals related to projects.

3) Complexity is a significant criterion in the chosen of an convenient project organizational form.

4) Complexity of project affects the chosen of project inputs, e.g. the knowledge and expertise requirements of administration personnel.

5) Complexity is generally used as a criterion in selecting the right project procurement arrangement.

6) Complexity impacts the project goals of time, quality and cost. Broadly, the bigger the project complexity the higher the proper time and cost.

\section{Construction projects complexity}

The complexity of Project is defined as the different parts interconnected with respect to the physical components and their interdependencies, as well as by adding the uncertainty components. The project 
complexity depends mainly on two factors: the difficulty of project and the risk of project. The difficulty of project is related to the team experience and team member skills. The risk of project identifies unknown factors affecting the project [15].

Project management complexity which represents an essential role in attaining the success of complex project management has been a significant part of project management. It is all the more important since complexity of projects is hotly debated and a factor which affects innovativeness of team performance. [16].

The main problem of project complexity administration is then for a project supervisor to know how exactly to seize the opportunities emerging from complexity also to learn how to avoid or at least diminish the negative effects of complexity [17].

\section{Construction projects complexity factors}

An actual number of factors retalted to complexity of project were explored. Major six elements were recognized which are after that furthermore divided into numerous sub factors as shown in table (2). Where major elements are as follows [18]:

1) The inherent complexity: A type of complex condition that is ultimately complex with a large number of various parts that have a large number of possible interconnections and feedback rings.

2) Uncertainty: refers to epistemic conditions involving incomplete or anonymous information. It applies to forecasts of future events, to particular physical measurements that are already made, or to the unknown. Uncertainty emerges in partially observable and/or chaotic environments, as well as due to unawareness, apathy, or both. It emerges in any field, including insurance, physics, statistics, economics, finance, sociology, engineering, and information science.

3) Technologies number: Technology is a set of techniques, skills, methods, and processes used to produce goods or services or to achieve objectives, such as scientific investigation. Technology can be the knowledge of particular techniques, processes, and other similar thing, or it can be included in machines to allow operation without detailed knowledge of its work. So, existing a large number of technology within the organization will increase the complexity and need for more planning and controlling.

4) Sequence rigidity: Means that there must be a logical sequence that is unchangeable or deviant for tasks, operations, and packages of operations within the phase.

5) Phases overlap: In an overlapping relationship, the next stage begins before the completion of the previous stage. Overlapping phases on occasion need extra resources because work must be done in parallel. The risk may increase or may lead to rework if the next phase is advanced before collecting the correct information from the preceding phase.

6) The inherent complexity of organization: It is defined as the amount of differentiation within the various elements that make up the organization. Often this number of different professional disciplines is run within the organization.

There are five dimensions of complexity are as follows [19]:

1) Cost; (Project estimates, Uncertainty, Contingency, Project-related costs (e.g., road-user costs, rightof-way), Project price constraints and drivers).

2) Planning; it is covering (Time, Schedule risk, Prescribed milestones, Availability of resources.

3) Technical; (Scope of work, Internal structure, Contract., Design, Construction, Technology, Nature of constraints).

4) Context; (Stakeholders, Project-specific issues, Local issues, Environmental issues, Legal and legislative problems, Global and national problems, Unexpected occurrences). 
5) Financing; (Public funding, Financing a future revenue stream, Exploiting asset value, Finance-driven project delivery methods, Financial ways to mitigate risk, Differential inflation rates, Commoditybased estimating.

\section{Research Methodology}

This part of the research indicates the steps that the researcher has taken to reach practical results, which are illustrated in the following flowchart in fig (1) and show the steps of field survey to evaluate the effects of complexity factors in Iraqi construction projects.

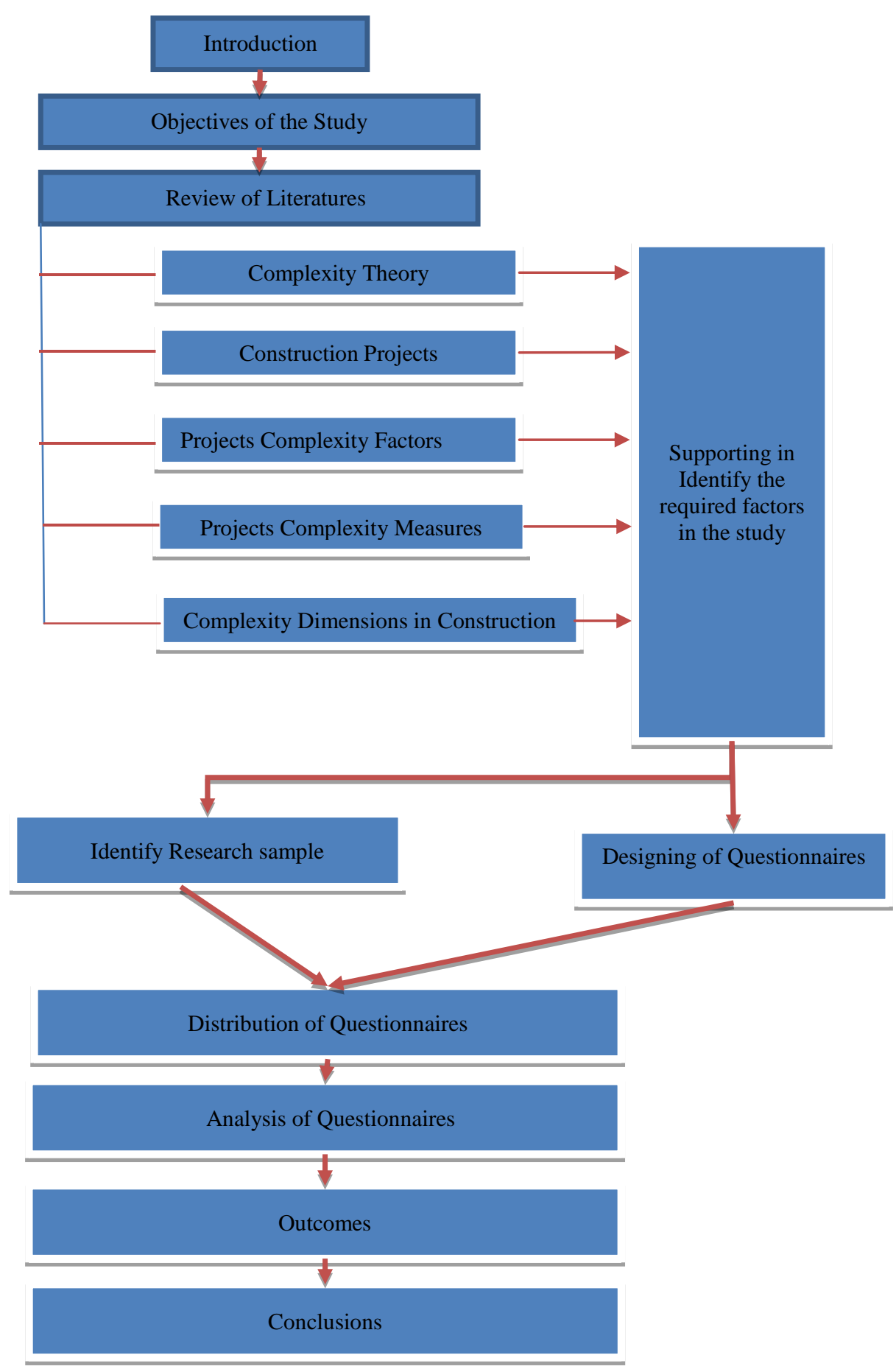

Figure 1. Research methodology 


\section{Design questionnaires}

This step refers to method of design questionnaires through communication with experts to arrangement the final form of questionnaires as in Appendix (A).

\subsection{The Sample of research}

The significant factor, that differentiates the process of closed questionnaire and its success, is the success of choosing the sample of research. The chosen research sample comprised of persons working in the following engineering domains [20]:

1- Site engineers, since some of the complexity problems are related to the site conditions.

2- Academic persons, since those individuals having enough knowledge about complexity factors and its effects.

3- Engineers in administrative positions, since some of the complexity problems are related to the organization.

The special case of the "central limit theorem" states that the distribution of the sample means approaches the normal distribution as the sample size increase, and that the distribution of the samples means from a normal population is always normal regardless of the sample size. [20]

The number of distributed questionnaire forms are (50), but only (45) had been answered and this number of forms enough to make statistical analysis because its larger than 30. Consequently, these (45) answered samples will be used as a grounds for the process of analysis. [20]

The closed questionnaire process comprised both state and private sectors working in different fields of construction to cover the two groups described above. Table (1) displays respondents number who participated in the questionnaire process.

Table 1. Respondents number and their organizations

\begin{tabular}{|c|c|c|}
\hline No. & Organization & Number of respondents \\
\hline 1 & World Energy Company for General Contracting Ltd. & 6 \\
\hline 2 & $\begin{array}{c}\text { The Ministry of Health / Department of Health } \\
\text { Baghdad - Rusafa. }\end{array}$ & 5 \\
\hline 3 & Al-Farabi university college. & 8 \\
\hline 5 & The Ministry of Housing and Construction. & 6 \\
\hline 6 & The Ministry of planning. & 6 \\
\hline 7 & Free space for General Trading and Contracting Ltd. & 6 \\
\hline 8 & $\begin{array}{c}\text { The Ministry of Electricity / Directorate of power } \\
\text { transmission projects. }\end{array}$ & 45 \\
\hline
\end{tabular}

\subsection{Analysis of questionnaire}

The results analysis depends on computation of frequencies number for the responses and the average weight of the responses to determine the preponderant respondents opinions by following the next steps[20]:

1- All questions have five options using likert scale for response analysis, where the response must be one of the following options:

\begin{tabular}{|l|l|l|c|c|} 
Totally ineffective & Slightly effective & effective & Moderately effective & Strongly effective \\
\hline
\end{tabular}


2- Firstly, the process of analysis starts with determining the frequencies number for any one of the five options.

3- To calculate the mean of responses, an interval is supposed for each option. The average weight is taken for each option of response, Table (2) describes the weights of responses for all options.

4- The mean was calculated according to the following equation:

$$
\mathrm{M}=\sum_{\mathrm{i}=1}^{\mathrm{i}=\mathrm{n}} \mathrm{Xi} * \mathrm{Fi} / \mathrm{N}
$$

where: $\mathrm{M}=$ Responses weighted mean about requirement.

$\mathrm{Xi}=$ Evaluation degree of response class ( i) about requirement .

$\mathrm{Fi}=$ Response frequency for class (i) about requirement.

$\mathrm{N}=$ Sample size in each requirement.

5- The analysis and evaluation results of the questionnaire for each items of the questionnaire depends on the extraction of median $(\mathrm{m})$ for the average value, which represents the middle value between 1 and 9then the mean equal to (5). And then extract the value of the top quarter of the average value between (1 and 9) and hence the highest quarter equal to 7 and then are analysed average for each items of the questionnaire according to the approaching of the above limits as follows:

If $M<5$ then the evaluation of the item is (poor) therefore the factor is ineffective and should be neglected.

If $5 \leq \mathrm{M} \leq 7$ then the evaluation of the item is (moderate) therefore the factor is effective and should be taking into account.

If $M>7$ then the evaluation of the item is (strong) therefore the factor is strongly effective and should be taking into account.

Table 2. Answers weight

\begin{tabular}{|c|c|c|}
\hline Type of answer & Interval & Average weight \\
\hline Totally ineffective & $0-2$ & 1 \\
\hline Slightly effective & $2-4$ & 3 \\
\hline effective & $4-6$ & 5 \\
\hline Moderately effective & $6-8$ & 7 \\
\hline Strongly effective & $8-10$ & 9 \\
\hline
\end{tabular}

\subsection{Results of the questionnaire}

The table below includes the final results of questionnaire conducted in the field of Iraqi construction projects.

Table 3. Questionnaire results

\begin{tabular}{|c|c|c|c|}
\hline \multicolumn{3}{|c|}{ The inherent complexity factors } \\
\hline Code & Factor & Mean & Evaluation \\
\hline Cf 1 & $\begin{array}{c}\text { Physically difficult role (without } \\
\text { equipment) }\end{array}$ & 7 & moderate \\
\hline Cf 2 & $\begin{array}{c}\text { Physically difficult role (with } \\
\text { complex equipment) }\end{array}$ & 6.86 & moderate \\
\hline
\end{tabular}


PEN Vol. 7, No. 4, December 2019, pp.2034- 2044

\begin{tabular}{|c|c|c|c|}
\hline Cf 3 & $\begin{array}{c}\text { Technically complex role } \\
\text { (sophistication of the equipment or } \\
\text { method) }\end{array}$ & 6.91 & moderate \\
\hline Cf 4 & $\begin{array}{c}\text { Technical complex role (requires } \\
\text { local available skills) }\end{array}$ & 2.87 & poor \\
\hline Cf 5 & $\begin{array}{c}\text { Technical complex role (requires a } \\
\text { particular skill, knowledge and tools) }\end{array}$ & 5.27 & moderate \\
\hline Cf 6 & Role that has no known procedure & 5.53 & moderate \\
\hline \multicolumn{4}{|c|}{ Uncertainty factors } \\
\hline Cf 7 & $\begin{array}{l}\text { Lack of uniformity due to lack of } \\
\text { working space and or access }\end{array}$ & 2.81 & poor \\
\hline Cf 8 & $\begin{array}{l}\text { Lack of constancy due to continual } \\
\text { change in materials or other resources }\end{array}$ & 6.96 & moderate \\
\hline Cf 9 & $\begin{array}{l}\text { Lack of constancy due to mechanical } \\
\text { inactivity or other resources }\end{array}$ & 3.76 & poor \\
\hline Cf 10 & The effects of weather & 3.53 & poor \\
\hline Cf 11 & $\begin{array}{l}\text { Unforeseeable sub-surface (e.g. } \\
\text { excavation in old areas) }\end{array}$ & 3.53 & poor \\
\hline Cf 12 & $\begin{array}{l}\text { Unforeseeable work in a located new } \\
\text { structure (e.g. new parts added to old } \\
\text { buildings without drawings) }\end{array}$ & 6.59 & moderate \\
\hline Cf 13 & $\begin{array}{l}\text { Indeterminate structure or lack of } \\
\text { build ability assessment (e.g. } \\
\text { rehabilitation works of ancient } \\
\text { buildings) }\end{array}$ & 6.24 & moderate \\
\hline Cf 14 & $\begin{array}{l}\text { Lack of working drawings (e.g. } \\
\text { investiture of mechnical and electrical } \\
\text { services in buildings) }\end{array}$ & 6.11 & moderate \\
\hline Cf 15 & Design build construction & 4.11 & poor \\
\hline Cf 16 & Due to environmental influence & 3.09 & poor \\
\hline Cf 17 & $\begin{array}{l}\text { Social/statutory/ecological layer (e.g. } \\
\text { identical project in a new position) }\end{array}$ & 3.13 & poor \\
\hline Cf 18 & $\begin{array}{l}\text { Technical core environmental layer } \\
\text { (e.g. construction under water) }\end{array}$ & 3.18 & poor \\
\hline Cf 19 & Lack of skilled local work force & 2.64 & poor \\
\hline Cf 20 & $\begin{array}{l}\text { Conducting or managing job for the } \\
\text { first time }\end{array}$ & 4.64 & poor \\
\hline \multicolumn{4}{|c|}{ Multiplicity of Technologies factors } \\
\hline Cf 21 & $\begin{array}{l}\text { Repetition of the roles in each } \\
\text { technology }\end{array}$ & 4.02 & poor \\
\hline Cf 22 & $\begin{array}{l}\text { Interdependencies between the jobs } \\
\text { of different technologies in a task }\end{array}$ & 7.16 & strong \\
\hline \multicolumn{4}{|c|}{ Sequence rigor factors } \\
\hline Cf 23 & Repetition of the same task & 2.91 & poor \\
\hline Cf 24 & $\begin{array}{l}\text { rigor of sequence between the } \\
\text { different tasks within an operation }\end{array}$ & 5.44 & moderate \\
\hline Cf 25 & rigor of sequence between the & 6.29 & moderate \\
\hline
\end{tabular}




\begin{tabular}{|l|c|c|c|}
\hline & different operations within a package & moderate \\
\hline Cf 26 & $\begin{array}{c}\text { rigor of sequence between the } \\
\text { different packages within a phase }\end{array}$ & 5.89 & moderate \\
\hline \multicolumn{5}{|c|}{ Phases interlock factors } \\
\hline Cf 27 & Degree of phases overlap & 5.53 & moderate \\
\hline Cf 28 & $\begin{array}{c}\text { Mutual relations between activities in } \\
\text { different overlapping parts }\end{array}$ & 6.69 & strong \\
\hline \multicolumn{4}{|c|}{ The rooted complexity of organization factors } \\
\hline Cf 29 & $\begin{array}{c}\text { Generation, usage,transmittal, and } \\
\text { feedback of information }\end{array}$ & 7.13 & moderate \\
\hline Cf 30 & Decision making & 6 & \\
\hline
\end{tabular}

\section{Conclusions}

Through the research paper, the nature of the complexities in the construction projects was reviewed in the Iraqi work environment. As the study is reflected that the degree of complexity in construction projects needs to know a set of factors that lead to the study of the degree of complexity, which is consistent with the theory of complexity. So that the complexity theory is an effective analysis tool in construction projects and in the work environment of project managers. Taking into consideration the classification of factors that got an influential ranking in the subject matter of study that Interdependencies between the roles of different technologies in a task and factor of Information generated transmittal, usage and feedback. and other factor under moderate evaluation are very interested to give the construction manager green line to take them in their consideration during work on both complex theory and complex project.

This theory can be used in the construction projects of Iraq, especially since there is a movement for the reconstruction of liberated areas, as these areas have already been damaged in a variety of life facilities and needed to accomplish different construction projects at the same time such as infrastructure projects, roads, and public buildings. As a result, the usage of complexity theory will enable us to plan, organize and execute all tasks in these areas within a single set of overlapping tasks. The completion of each project depends on the success of the other projects. Finally, Complexity theory can help us to recthfy our understanding about organizations under study. It educates us how to think about the evolutionary process.

\section{Dicrepancy of interest}

The authors state that there is no dicrepancy of interest. 


\section{References}

[1] D. Z., and B. Ian, "Complexity theory and knowledge management application," Electronic Journal of Knowledge Management Volume 4 Issue 1: Liverpool John Moores University, UK, 2006.

[2] M. M. and N. Ruxandra, "The Nature of the Relationship between Project Complexity and Project Delay: Case study of ERP system implementation projects,” Master thesis, Faculty of Social Sciences, 2012.

[3] D. P. Bac, "Exploring and Measuring Project Complexity," A dissertation submitted to the office of graduate and professional studies of Texas A \& M university, Doctor of Philosophy, August 2016.

[4] U. Omoregie, "Megaprojects, Complexity, and Investment Decisions," Open Journal of Business and Management, vol. 04, no. 02, pp. 219-224, 2016.

[5] J. Rotmans and D. Loorbach, "Complexity and Transition Management," Journal of Industrial Ecology, vol. 13, no. 2, pp. 184-196, Apr. 2009.

[6] A. B. I. Al-Fatlawi AA, Mohammed GN, "Optimizing the Performance of Clouds Using Hash Codes in Apache Hadoop and Spark.," J. Southwest Jiaotong Univ., vol. 54, no. 6, 2019.

[7]R. E. Giovanni, "Complexity Theory and Applications To Management: Principles Regarding Business Coherence and Fluent Operative Systems Within Enterprises," 1(1), 90-101, Sep. 2013.

[8] R. T. Hazem and H. K. Breesam, "Development of Possible Solution to Overcome Factors Influence on Sustainable Construction Process," Civil Engineering Journal, vol. 5, no. 7, pp. 1506-1517, Jul. 2019.

[9] V. Rodríguez Montequín, J. Villanueva Balsera, S. M. Cousillas Fernández, and F. Ortega Fernández, "Exploring Project Complexity through Project Failure Factors: Analysis of Cluster Patterns Using SelfOrganizing Maps," Complexity, vol. 2018, pp. 1-17, 2018.

[10] H. Maylor and N. Turner, "Understand, Reduce, Respond: Project complexity management theory and practice," Academy of Management Proceedings, vol. 2016, no. 1, p. 12213, Jan. 2016.

[11] J. R. San Cristóbal, L. Carral, E. Diaz, J. A. Fraguela, and G. Iglesias, "Complexity and Project Management: A General Overview,” Complexity, vol. 2018, pp. 1-10, Oct. 2018.

[12]P. Tosey, "Teaching on The Edge of Choas: Complexity Theory , Learning Systems And Enhancement," Educational Studies, University of Surrey: 1-23. Retrieved from, May 2002.

[13] E. Asnaashari, "A Holistic Conceptual Model for Managing Construction Logistics in Building Projects : the Case of Iran," A thesis submitted in partial fulfilment of the requirements of Nottingham Trent University for the degree of Doctor of Philosophy, Nov. 2011.

[14] H. L. Wood, P. Poorang, and R. P. Eric Farr, "Understanding Complexity in the AEC Industry," 29th Annual ARCOM Conference: 859-869, Sep. 2013.

[15] B. Priyadharsini, and V. Rathinakumar, "Assessment of Factors Influencing Construction Project Complexity (CPC)," International Journal of Civil Engineering and Technology (IJCIET) Volume 9, Issue 4. April 2018.

[16] I. A. B. Sawsan Ali Hamid, Rana Alauldeen Abdalrahman , Inam Abdullah Lafta, "Web Services Architecture Model to Support Distributed Systems," J. SOUTHWEST JIAOTONG Univ. Vol., vol. 54, no. December, pp. 52-57, 2019. 
[17] L. Vidal and F. Marle, "Understanding project complexity: implications on project management," Kybernetes, vol. 37, no. 8, pp. 1094-1110, Sep. 2008.

[18] H. Wood, and A. Philip, "Factors of Complexity in Construction Projects," In: Dainty, A. (Ed) Procs 25th Annual ARCOM Conference. Sep. 2009.

[19] J. Shane, K. Strong, and D. Gransberg, "Guide to Project Management Strategies for Complex Projects," Mar. 2013.

[20] F. A. Hayder, "Development of a Computer Program for Valuation the Arab Safety Code Applications in Construction Projects in Iraq," A master thesis submitted to civil engineering department/Baghdad University, Jan. 2014. 